\title{
IDENTIFICATION OF THE LEADING RESEARCH DOMAINS AND GROUPING OF ARTICLES ON THE SMART CITY USING TEXT MINING
}

\author{
Dariusz ZDONEK \\ Silesian University of Technology in Gliwice, Faculty of Organisation and Management; \\ dariusz.zdonek@polsl.pl, ORCID: 0000-0002-6190-9643
}

Purpose: The objective of the paper is to use text mining to identify leading research domains concerning the smart city following an analysis of research articles with a high citation index according to the Web of Science.

Design/methodology/approach: An original method is proposed for analysing academic texts using the $\mathrm{R}$ language, tokenisation, lemmatisation, n-grams and correspondence analysis. The author analysed fifty of the most cited articles indexed in the Web of Science from 2014 to 2019.

Findings: The paper presents the advantages and drawbacks of the proposed method of analysing research publications. The assets include automation and repeatability of the analysis of a large number of documents and improved knowledge about links among the articles in terms of research domains. The disadvantage is the loss of information from diagrams and figures. The method identified two leading research domains related to the notion of the smart city, technologies and systems. The analysed publications were categorised by selected keywords.

Research limitations/implications: Future work should include further refinement of the assumptions for the method, analyses of a more significant number of research texts and a narrowing down of the domain of the smart city. It is desirable to consider other functional domains of the city, such as energy, public health, environmental protection or transport.

Practical implications: The proposed method can complement a standard literature analysis regarding the smart city. The leading research domains related to the smart city in the analysed articles were systems and technologies employed to improve how the city operates.

Social implications: Text mining can be employed by various experts focusing on the smart city and constitutes a refreshing complement for other research methods, such as questionnaire surveys, interviews or observations.

Originality/value The publication can be useful for researchers from various fields and managers seeking to create and use simple, useful methods and tools for analysing unstructured text documents for decision-making. The paper proposes a separate text mining analysis of abstracts and whole documents using n-grams. This yielded a more precise list of areas relevant to the smart city. The grouping was done using correspondence analysis of the fifty most cited articles indexed in the Web of Science from 2014 to 2019.

Keywords: smart city, text mining, information and communication technology, scientific papers, research areas. 


\section{Introduction}

The development of the Internet and global digitalisation change how business, industry, entertainment and cities work. This, in turn, affects global societal changes. The increasingly popular notion of the smart city has many definitions in literature (Albino et al., 2015). In simple terms, the smart city is defined as an urban area that uses various types of electronic sensors to collect data and then employs the resulting insight for efficient management of its assets, resources and services (Wikipedia, 2019). Deakin (2013) and A. I. Wear (Deakin and Wear, 2011) define the smart city as one that utilises ICT to meet the demands of its citizens. They believe the community involvement in the process is necessary and list factors that define the smart city.

Interest the smart city has grown dynamically since 2010 and remains constant today. This is apparent from plots on Google Trends (2019) and the numbers of publications in the Web of Science (Fig. 1).

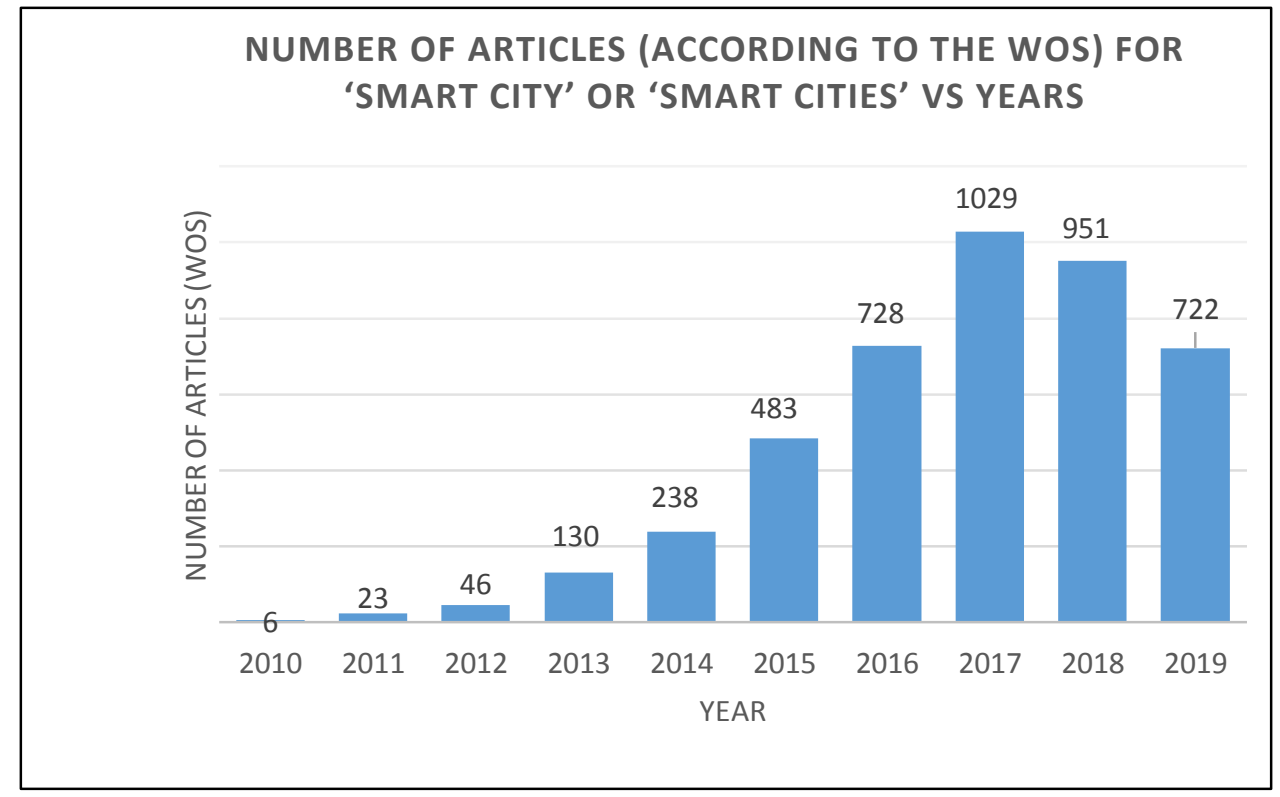

Figure 1. Number of articles (according to the WoS) for 'smart city' or 'smart cities' 2010-2019 (28.11.2019). Source: own work based on https://apps.webofknowledge.com.

Research topics concerning the smart city are growing broader. It is ever more difficult, and mostly even impossible, to keep track of and be familiar with all new publications in this domain, which can focus on technical, social and organisational aspects. Academic efforts yield publications that most often contain structured data, such as tables, and semi-structured data, such as text, pictures or diagrams. In the current era of global digitalisation and Internet prevalence, the amount of data and number of publications is prolific. Hence, there is more and more urgent need for tools and methods that could process and analyse such large amount of data automatically. This applies to structured data in databases and semi-structured textual data. This has put data exploration methods in the spotlight. One of these is text mining, which 
searches for unusual patterns in large textual datasets to extract new information from textual resources.

The objective of the paper is to attempt to identify leading research domains concerning the smart city following a text mining analysis of research articles with a high citation index according to the Web of Science.

The author included 50 selected research articles dating from 2014 to 2019, published in two leading journals. Another goal is to find the faults and good points of the application of text mining for identifying research domains concerning the smart city.

\section{Text mining for research article analysis}

Text mining involves the automated extraction of useful information from textual data. Automation requires programming or appropriate software. According to Suhaib Peerzada, 'text mining is a tool which helps in getting the data cleaned up. Text mining techniques are basically cleaning up unstructured data to be available for text analytics'. He specified several steps to be followed during text mining. These are tokenisation, stemming and lemmatisation, stop words, number and punctuation removal, converting to lowercase, POS tagging, creating text corpus and term-document matrix (Peerzada, 2018). Each step modifies unstructured data to yield as much structured data as possible valuable to the user.

Other authors usually proposed four basic processes for text mining: tokenisation, removal of stop words, stemming and POS tagging (Fan et al., 2006; Vijayarani et al., 2015; Silge and Robinson, 2017). Text mining can be approached differently depending on user needs and the types of analysed documents. Research texts are structured in a particular way and consist of a title, author(s), abstract, keywords, introduction, literature review, method, results, discussion, conclusion, references and acknowledgements. The specific structure depends on the journal and author, as there is no one universal template. Still, some standards are generally accepted and pursued, such as EASE (EASE Guidelines, 2019) or IMRAD (Sollaci, 2004; Mogull, 2017).

Today, it is much easier to gain access to global research publications than a dozen years ago thanks to the Internet and the internationalisation of science. More and more publishing houses offer their resources online for free or for a small charge. This provides access to a considerable number of papers from various disciplines. The author decided to focus on research articles concerning the smart city that have a high citation index. 


\section{Materials, methods and tools}

The paper analyses the most cited papers according to the Web of Science Core Collection from 2014 to 2019, available online. The layout of the articles was found to differ significantly depending on the publisher. The selection of journals was narrowed down to Sustainable Cities and Society and IEEE Access. They were one of the most cited journals on the list, and the author intended to focus on technologies and research problems related to the smart city.

The results were limited to the keywords 'smart city' and 'smart cities' in titles. The analysis involved 50 research articles on the smart city. The list of downloaded articles subjected to text mining can be found in Table 1. The documents were obtained as PDF files. The research process took place from November to December 2019.

Table 1.

Most cited research articles about 'smart city' and 'smart cities' according to the Web of Science published from 2014 to 2019

\begin{tabular}{|c|c|c|c|}
\hline \multirow[t]{2}{*}{ Id } & \multirow{2}{*}{ Article } & \multicolumn{2}{|c|}{ Times Cited by } \\
\hline & & WoS & Scholar \\
\hline 1 & $\begin{array}{l}\text { Kylili, A. \& Fokaides, P. A. (2015). European smart cities: The role of zero energy } \\
\text { buildings. Sustainable cities and society, 15, pp. 86-95. }\end{array}$ & 94 & 183 \\
\hline 2 & $\begin{array}{l}\text { Silva, B. N., Khan, M. \& Han, K. (2018). Towards sustainable smart cities: A } \\
\text { review of trends, architectures, components, and open challenges in smart cities. } \\
\text { Sustainable Cities and Society, 38, pp. } 697-713 \text {. }\end{array}$ & 60 & 162 \\
\hline 3 & $\begin{array}{l}\text { Puiu, D., Barnaghi, P., Tönjes, R., Kümper, D., Ali, M. I., Mileo, A., ... \& Gao, F. } \\
\text { (2016). Citypulse: Large scale data analytics framework for smart cities. IEEE } \\
\text { Access, 4, pp. 1086-1108. }\end{array}$ & 59 & 117 \\
\hline 4 & $\begin{array}{l}\text { Wu, J., Ota, K., Dong, M. \& Li, C. (2016). A hierarchical security framework for } \\
\text { defending against sophisticated attacks on wireless sensor networks in smart cities. } \\
\text { IEEE Access, 4, pp. 416-424. }\end{array}$ & 54 & 83 \\
\hline 5 & $\begin{array}{l}\text { Mattoni, B., Gugliermetti, F. \& Bisegna, F. (2015). A multilevel method to assess } \\
\text { and design the renovation and integration of Smart Cities. Sustainable Cities and } \\
\text { Society, 15, pp. 105-119. }\end{array}$ & 54 & 117 \\
\hline 6 & $\begin{array}{l}\text { Pouryazdan, M., Kantarci, B., Soyata, T. \& Song, H. (2016). Anchor-assisted and } \\
\text { vote-based trustworthiness assurance in smart city crowdsensing. IEEE Access, } 4 \text {, } \\
\text { pp. 529-541. }\end{array}$ & 52 & 85 \\
\hline 7 & $\begin{array}{l}\text { Mohamed, N., Al-Jaroodi, J., Jawhar, I., Lazarova-Molnar, S. \& Mahmoud, S. } \\
\text { (2017). SmartCityWare: A service-oriented middleware for cloud and fog enabled } \\
\text { smart city services. IEEE Access, 5, pp. 17576-17588. }\end{array}$ & 37 & 58 \\
\hline 8 & $\begin{array}{l}\text { Liu, J., Xiong, K., Fan, P. \& Zhong, Z. (2017). RF energy harvesting wireless } \\
\text { powered sensor networks for smart cities. IEEE Access, 5, pp. 9348-9358. }\end{array}$ & 29 & 37 \\
\hline 9 & $\begin{array}{l}\text { Alvi, A. N., Bouk, S. H., Ahmed, S. H., Yaqub, M. A., Sarkar, M. \& Song, H. } \\
\text { (2016). BEST-MAC: Bitmap-assisted efficient and scalable TDMA-based WSN } \\
\text { MAC protocol for smart cities. IEEE Access, 4, pp. 312-322. }\end{array}$ & 27 & 46 \\
\hline 10 & $\begin{array}{l}\text { Chen, L. J., Ho, Y. H., Lee, H. C., Wu, H. C., Liu, H. M., Hsieh, H. H., ... \& Lung, } \\
\text { S. C. C. (2017). An open framework for participatory PM2. } 5 \text { monitoring in smart } \\
\text { cities. IEEE Access, 5, pp. 14441-14454. }\end{array}$ & 25 & 41 \\
\hline 11 & $\begin{array}{l}\text { Ullah, R., Faheem, Y. \& Kim, B. S. (2017). Energy and congestion-aware routing } \\
\text { metric for smart grid AMI networks in smart city. IEEE access, 5, pp. 13799- } \\
13810 .\end{array}$ & 22 & 41 \\
\hline 12 & $\begin{array}{l}\text { Teng, H., Liu, W., Wang, T., Liu, A., Liu, X. \& Zhang, S. (2019). A cost-efficient } \\
\text { greedy code dissemination scheme through vehicle to sensing devices (V2SD) } \\
\text { communication in smart city. IEEE Access, 7, pp. 16675-16694. }\end{array}$ & 21 & 26 \\
\hline
\end{tabular}


Cont. table 1.

\begin{tabular}{|c|c|c|c|}
\hline 13 & $\begin{array}{l}\text { Sotres, P., Santana, J. R., Sánchez, L., Lanza, J. \& Munoz, L. (2017). Practical } \\
\text { lessons from the deployment and management of a smart city Internet-of-Things } \\
\text { infrastructure: The smartsantander testbed case. IEEE Access, 5, pp. 14309-14322. }\end{array}$ & 21 & 38 \\
\hline 14 & $\begin{array}{l}\text { Muhammad, G., Alsulaiman, M., Amin, S. U., Ghoneim, A. \& Alhamid, M. F. } \\
\text { (2017). A facial-expression monitoring system for improved healthcare in smart } \\
\text { cities. IEEE Access, 5, pp. 10871-10881. }\end{array}$ & 20 & 37 \\
\hline 15 & $\begin{array}{l}\text { Sajjad, M., Khan, S., Jan, Z., Muhammad, K., Moon, H., Kwak, J. T., ... \& } \\
\text { Mehmood, I. (2016). Leukocytes classification and segmentation in microscopic } \\
\text { blood smear: a resource-aware healthcare service in smart cities. IEEE Access, 5, } \\
\text { pp. 3475-3489. }\end{array}$ & 19 & 36 \\
\hline 16 & $\begin{array}{l}\text { Chen, B. W., Ji, W., Jiang, F. \& Rho, S. (2015). QoE-enabled big video streaming } \\
\text { for large-scale heterogeneous clients and networks in smart cities. IEEE Access, } 4 \text {, } \\
\text { pp. 97-107. }\end{array}$ & 18 & 23 \\
\hline 17 & $\begin{array}{l}\text { Muhammed, T., Mehmood, R., Albeshri, A. \& Katib, I. (2018). UbeHealth: a } \\
\text { personalised ubiquitous cloud and edge-enabled networked healthcare system for } \\
\text { smart cities. IEEE Access, 6, pp. 32258-32285. }\end{array}$ & 17 & 45 \\
\hline 18 & $\begin{array}{l}\text { Samani, H. \& Zhu, R. (2016). Robotic automated external defibrillator ambulance } \\
\text { for emergency medical service in smart cities. IEEE Access, 4, pp. 268-283. }\end{array}$ & 17 & 27 \\
\hline 19 & $\begin{array}{l}\text { Islam, M. M., Razzaque, M. A., Hassan, M. M., Ismail, W. N. \& Song, B. (2017). } \\
\text { Mobile cloud-based big healthcare data processing in smart cities. IEEE Access, 5, } \\
\text { pp. 11887-11899. }\end{array}$ & 16 & 41 \\
\hline 20 & $\begin{array}{l}\text { Brisimi, T. S., Cassandras, C. G., Osgood, C., Paschalidis, I. C. \& Zhang, Y. } \\
\text { (2016). Sensing and classifying roadway obstacles in smart cities: The street bump } \\
\text { system. IEEE Access, 4, pp. 1301-1312. }\end{array}$ & 16 & 26 \\
\hline 21 & $\begin{array}{l}\text { Braun, T., Fung, B. C., Iqbal, F. \& Shah, B. (2018). Security and privacy } \\
\text { challenges in smart cities. Sustainable cities and society, 39, pp. 499-507. }\end{array}$ & 14 & 39 \\
\hline 22 & $\begin{array}{l}\text { Massana, J., Pous, C., Burgas, L., Melendez, J. \& Colomer, J. (2017). Identifying } \\
\text { services for short-term load forecasting using data driven models in a Smart City } \\
\text { platform. Sustainable cities and society, 28, pp. 108-117. }\end{array}$ & 14 & 27 \\
\hline 23 & $\begin{array}{l}\text { Jia, G., Han, G., Jiang, J., Sun, N. \& Wang, K. (2015). Dynamic resource } \\
\text { partitioning for heterogeneous multi-core-based cloud computing in smart cities. } \\
\text { IEEE Access, 4, pp. 108-118. }\end{array}$ & 14 & 19 \\
\hline 24 & $\begin{array}{l}\text { Raman, R., Sa, P. K., Majhi, B. \& Bakshi, S. (2016). Direction estimation for } \\
\text { pedestrian monitoring system in smart cities: An HMM based approach. IEEE } \\
\text { Access, 4, pp. 5788-5808. }\end{array}$ & 14 & 19 \\
\hline 25 & $\begin{array}{l}\text { Ianuale, N., Schiavon, D. \& Capobianco, E. (2015). Smart cities, big data, and } \\
\text { communities: Reasoning from the viewpoint of attractors. IEEE Access, 4, pp. 41- } \\
47 .\end{array}$ & 13 & 23 \\
\hline 26 & $\begin{array}{l}\text { Bonafoni, S., Baldinelli, G. \& Verducci, P. (2017). Sustainable strategies for smart } \\
\text { cities: Analysis of the town development effect on surface urban heat island } \\
\text { through remote sensing methodologies. Sustainable Cities and Society, 29, pp. } \\
\text { 211-218. }\end{array}$ & 12 & 23 \\
\hline 27 & $\begin{array}{l}\text { Cui, L., Xie, G., Qu, Y., Gao, L. \& Yang, Y. (2018). Security and privacy in smart } \\
\text { cities: Challenges and opportunities. IEEE access, 6, pp. 46134-46145. }\end{array}$ & 10 & 28 \\
\hline 28 & $\begin{array}{l}\text { Ali, Z., Muhammad, G. \& Alhamid, M. F. (2017). An automatic health monitoring } \\
\text { system for patients suffering from voice complications in smart cities. IEEE } \\
\text { Access, 5, pp. 3900-3908. }\end{array}$ & 10 & 29 \\
\hline 29 & $\begin{array}{l}\text { Alhussein, M. (2017). Monitoring Parkinson's disease in smart cities. IEEE } \\
\text { Access, 5, pp. 19835-19841 }\end{array}$ & 9 & 24 \\
\hline 30 & $\begin{array}{l}\text { Qiu, J., Chai, Y., Liu, Y., Gu, Z., Li, S. \& Tian, Z. (2018). Automatic non- } \\
\text { taxonomic relation extraction from big data in smart city. IEEE Access, 6, pp. } \\
\text { 74854-74864. }\end{array}$ & 8 & 17 \\
\hline 31 & $\begin{array}{l}\text { Lella, J., Mandla, V. R. \& Zhu, X. (2017). Solid waste collection/transport } \\
\text { optimisation and vegetation land cover estimation using Geographic Information } \\
\text { System (GIS): A case study of a proposed smart-city. Sustainable cities and } \\
\text { society, 35, pp. 336-349. }\end{array}$ & 8 & 16 \\
\hline 32 & $\begin{array}{l}\text { Won, J., Seo, S. H. \& Bertino, E. (2017). Certificateless cryptographic protocols } \\
\text { for efficient drone-based smart city applications. IEEE Access, 5, pp. 3721-3749. }\end{array}$ & 8 & 18 \\
\hline
\end{tabular}


Cont. table 1.

\begin{tabular}{|c|c|c|c|}
\hline 33 & $\begin{array}{l}\text { De Filippi, F., Coscia, C., Boella, G., Antonini, A., Calafiore, A., Cantini, A., ... \& } \\
\text { Schifanella, C. (2016). MiraMap: A We-government tool for smart peripheries in } \\
\text { Smart Cities. IEEE Access, 4, pp. 3824-3843. }\end{array}$ & 8 & 19 \\
\hline 34 & $\begin{array}{l}\text { Kulkarni, P. \& Farnham, T. (2016). Smart city wireless connectivity considerations } \\
\text { and cost analysis: Lessons learnt from smart water case studies. IEEE Access, } 4 \text {, } \\
\text { pp. } 660-672 \text {. }\end{array}$ & 8 & 17 \\
\hline 35 & $\begin{array}{l}\text { Li, X., Lv, Z., Hijazi, I. H., Jiao, H., Li, L. \& Li, K. (2016). Assessment of urban } \\
\text { fabric for smart cities. IEEE Access, 4, pp. 373-382. }\end{array}$ & 8 & 16 \\
\hline 36 & $\begin{array}{l}\text { Yadav, G., Mangla, S. K., Luthra, S. \& Rai, D. P. (2019). Developing a sustainable } \\
\text { smart city framework for developing economies: An Indian context. Sustainable } \\
\text { Cities and Society, 47, p. } 101462 \text {. }\end{array}$ & 7 & 14 \\
\hline 37 & $\begin{array}{l}\text { Gohar, M., Muzammal, M. \& Rahman, A. U. (2018). SMART TSS: Defining } \\
\text { transportation system behavior using big data analytics in smart cities. Sustainable } \\
\text { cities and society, } 41 \text {, pp. 114-119. }\end{array}$ & 6 & 18 \\
\hline 38 & $\begin{array}{l}\text { Anisetti, M., Ardagna, C., Bellandi, V., Cremonini, M., Frati, F. \& Damiani, E. } \\
\text { (2018). Privacy-aware Big Data Analytics as a service for public health policies in } \\
\text { smart cities. Sustainable cities and society, 39, pp. } 68-77 \text {. }\end{array}$ & 6 & 20 \\
\hline 39 & $\begin{array}{l}\text { Usman, M., Asghar, M. R., Ansari, I. S., Granelli, F. \& Qaraqe, K. A. (2018). } \\
\text { Technologies and solutions for location-based services in smart cities: Past, } \\
\text { present, and future. IEEE Access, 6, pp. 22240-22248. }\end{array}$ & 6 & 10 \\
\hline 40 & $\begin{array}{l}\text { Jain, B., Brar, G., Malhotra, J. \& Rani, S. (2017). A novel approach for smart cities } \\
\text { in convergence to wireless sensor networks. Sustainable cities and society, 35, pp. } \\
440-448 \text {. }\end{array}$ & 6 & 14 \\
\hline 41 & $\begin{array}{l}\text { Kotevska, O., Kusne, A. G., Samarov, D. V., Lbath, A. \& Battou, A. (2017). } \\
\text { Dynamic network model for smart city data-loss resilience case study: City-to-city } \\
\text { network for crime analytics. IEEE Access, 5, pp. 20524-20535. }\end{array}$ & 5 & 6 \\
\hline 42 & $\begin{array}{l}\text { Vázquez-Canteli, J. R., Ulyanin, S., Kämpf, J. \& Nagy, Z. (2019). Fusing } \\
\text { TensorFlow with building energy simulation for intelligent energy management in } \\
\text { smart cities. Sustainable cities and society, 45, pp. 243-257. }\end{array}$ & 5 & 19 \\
\hline 43 & $\begin{array}{l}\text { Vo, N. S., Duong, T. Q., Guizani, M. \& Kortun, A. (2018). 5G optimised caching } \\
\text { and downlink resource sharing for smart cities. IEEE Access, 6, pp. 31457-31468. }\end{array}$ & 5 & 24 \\
\hline 44 & $\begin{array}{l}\text { Khan, M., Babar, M., Ahmed, S. H., Shah, S. C. \& Han, K. (2017). Smart city } \\
\text { designing and planning based on big data analytics. Sustainable cities and society, } \\
\text { 35, pp. 271-279. }\end{array}$ & 5 & 18 \\
\hline 45 & $\begin{array}{l}\text { Deng, Y., Chen, Z., Yao, X., Hassan, S. \& Wu, J. (2019). Task scheduling for } \\
\text { smart city applications based on multi-server mobile edge computing. IEEE } \\
\text { Access, 7, pp. 14410-14421. }\end{array}$ & 4 & 8 \\
\hline 46 & $\begin{array}{l}\text { Aborokbah, M. M., Al-Mutairi, S., Sangaiah, A. K. \& Samuel, O. W. (2018). } \\
\text { Adaptive context aware decision computing paradigm for intensive health care } \\
\text { delivery in smart cities-A case analysis. Sustainable cities and society, 41, pp. } \\
\text { 919-924. }\end{array}$ & 5 & 15 \\
\hline 47 & $\begin{array}{l}\text { Khan, Z. A. (2018). Using energy-efficient trust management to protect IoT } \\
\text { networks for smart cities. Sustainable cities and society, 40, pp. 1-15. }\end{array}$ & 4 & 9 \\
\hline 48 & $\begin{array}{l}\text { Malik, K. R., Sam, Y., Hussain, M. \& Abuarqoub, A. (2018). A methodology for } \\
\text { real-time data sustainability in smart city: Towards inferencing and analytics for } \\
\text { big-data. Sustainable cities and society, 39, pp. 548-556. }\end{array}$ & 4 & 15 \\
\hline 49 & $\begin{array}{l}\text { Wan, S., Lu, J., Fan, P. \& Letaief, K. B. (2017). To smart city: Public safety } \\
\text { network design for emergency. IEEE access, 6, pp. 1451-1460. }\end{array}$ & 4 & 10 \\
\hline 50 & $\begin{array}{l}\text { Wu, M., Xiong, N. N. \& Tan, L. (2018). An intelligent adaptive algorithm for } \\
\text { environment parameter estimation in smart cities. IEEE Access, 6, pp. 23325- } \\
23337 \text {. }\end{array}$ & 4 & 7 \\
\hline
\end{tabular}

Source: own work based on the Web of Science (https://apps.webofknowledge.com, 2019.11.28). 


\subsection{Methods}

The research consisted of ten procedural stages (Fig. 2).

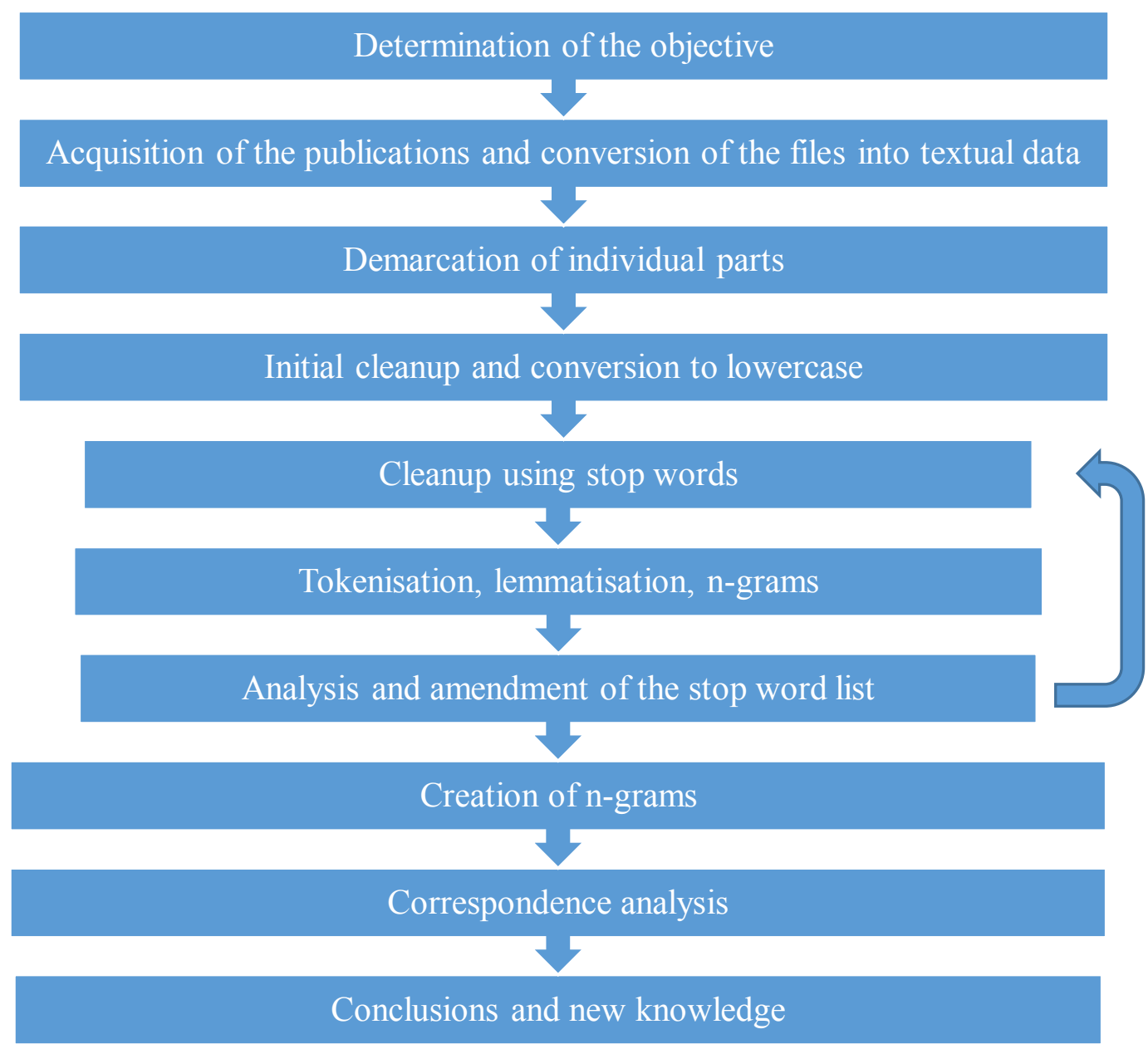

Figure 2. Stages of the research. Source: own work.

The first two stages involved the determination of the study objective and collection of articles to be analysed following conversion into textual data. The articles were found using a website at https://apps.webofknowledge.com, where articles indexed by the WoS can be searched. The PDF files were converted to .txt with an online tool available at https://pdftotext.com $/ \mathrm{pl}$. The third stage saw all the data in text files loaded into an analytical tool and divided into characteristic parts. A script in R searched for the words 'introduction' and 'references' and divided each text into three separate parts. It the fourth stage, words and phrases characteristic of specific publishers were removed (IEEE Access, sustainable cities and similar), all characters were converted to lowercase. The fifth stage involved cleaning the data using a list of stop words. The sixth stage was tokenisation, lemmatisation and n-grams. Tokenisation meant parsing the data into individual words. Lemmatisation changed plurals into singulars and converted all words into their respective lemmas. Stop words were used to remove words that were insignificant for analytical purposes (such as: the, a, an, in). For each process, selected packages and functions of libraries tidytext, textstem and $\mathrm{tm}$ for $\mathrm{R}$ were used. Word frequency statistics were built at this stage using n-grams. Approx. 10\% of the most common 
words in each document were analysed. If necessary, new words or phrases that should be excluded from text mining were added to the stop word list. Following such amendments, the author returned to step five; hence the iterative loop in the method. This was repeated each time the stop words list was amended. The author considered using POS tags (Nakagawa et al., 2007), which flags words with the correct part of speech (such as noun, adjective or verb), but deemed it not necessary for this particular study. The eighth step was to build n-grams, followed by a correspondence analysis in the ninth step. The last stage was to interpret the results to create new knowledge about the investigated documents. The method was applied to whole texts excluding references (TXT), and separately to abstracts only (ABS).

\subsection{Results}

Using the assumptions and steps described in the previous section, the author investigated 50 documents presented in Table 2. After many iterations of data cleaning at stages four and five, the method yielded a list of the most common words related to the smart city. The study of whole articles (TXT) involved 12,500 words, 40\% of which were used once in all the documents. The most common words were data, smart, city, system, network, base, energy, time, node, application, service, device, propose, model, sensor and so on (Fig. 3).

\begin{tabular}{|c|c|c|}
\hline No. & Word & Freq. \\
\hline 1 & data & 3114 \\
\hline 2 & smart & 2528 \\
\hline 3 & city & 2398 \\
\hline 4 & system & 1689 \\
\hline 5 & network & 1477 \\
\hline 6 & base & 1272 \\
\hline 7 & energy & 1158 \\
\hline 8 & time & 1145 \\
\hline 9 & node & 977 \\
\hline 10 & application & 957 \\
\hline 11 & service & 952 \\
\hline 12 & device & 933 \\
\hline 13 & propose & 920 \\
\hline 14 & model & 909 \\
\hline 15 & sensor & 878 \\
\hline
\end{tabular}

\begin{tabular}{|c|c|c|}
\hline No. & Word & Freq. \\
\hline 16 & information & 821 \\
\hline 17 & user & 766 \\
\hline 18 & provide & 732 \\
\hline 19 & process & 728 \\
\hline 20 & set & 661 \\
\hline 21 & figure & 648 \\
\hline 22 & numb & 640 \\
\hline 23 & task & 639 \\
\hline 24 & algorithm & 636 \\
\hline 25 & result & 632 \\
\hline 26 & communication & 569 \\
\hline 27 & technology & 551 \\
\hline 28 & performance & 534 \\
\hline 29 & resource & 523 \\
\hline 30 & cost & 515 \\
\hline
\end{tabular}

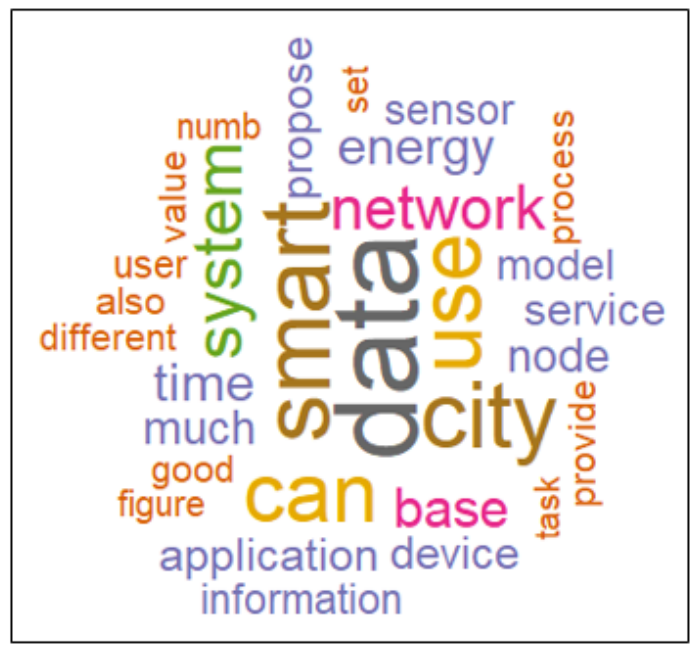

Figure 3. Single words, whole articles without references (TXT). Source: own work using R and RStudio.

For abstracts of the articles (ABS), the analysis yielded approx. 1,500 words, $47 \%$ of which were used once in all the documents. The most common words were smart, city, data, system, propose, base, network, energy, paper, service, technology and so on (Fig. 4). 


\begin{tabular}{|c|c|c|}
\hline No. & Word & Freq. \\
\hline 1 & smart & 155 \\
\hline 2 & city & 154 \\
\hline 3 & data & 100 \\
\hline 4 & system & 71 \\
\hline 5 & propose & 68 \\
\hline 6 & base & 52 \\
\hline 7 & network & 50 \\
\hline 8 & energy & 46 \\
\hline 9 & paper & 46 \\
\hline 10 & service & 40 \\
\hline 11 & technology & 37 \\
\hline 12 & information & 36 \\
\hline 13 & provide & 35 \\
\hline 14 & application & 32 \\
\hline 15 & time & 32 \\
\hline
\end{tabular}

\begin{tabular}{|c|c|c|}
\hline No. & Word & Freq. \\
\hline 16 & framework & 31 \\
\hline 17 & improve & 31 \\
\hline 18 & resource & 31 \\
\hline 19 & urban & 31 \\
\hline 20 & sensor & 30 \\
\hline 21 & communication & 28 \\
\hline 22 & iot & 27 \\
\hline 23 & performance & 26 \\
\hline 24 & result & 26 \\
\hline 25 & device & 24 \\
\hline 26 & quality & 23 \\
\hline 27 & algorithm & 22 \\
\hline 28 & life & 22 \\
\hline 29 & monitor & 22 \\
\hline 30 & support & 22 \\
\hline
\end{tabular}

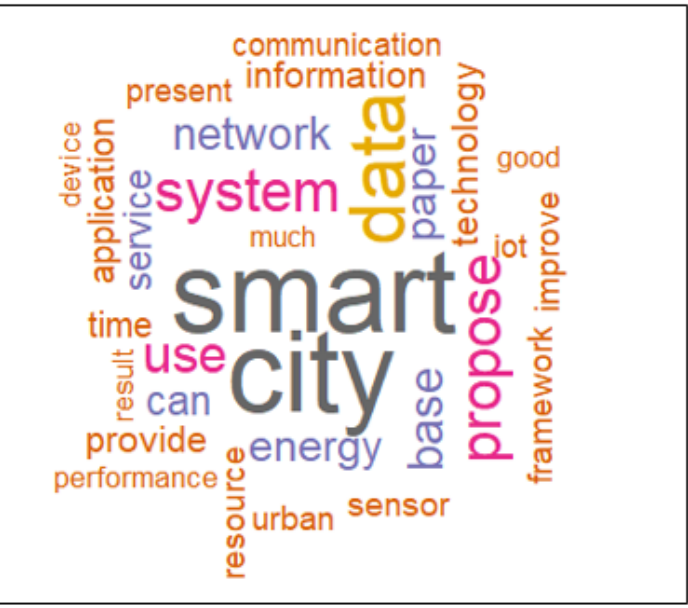

Figure 4. Single words, abstracts (ABS). Source: own work using R and RStudio.

A total of $21(70 \%)$ items out of the 30 most frequent words are the same for TXT and ABS. $71 \%$ of the first 100 words were the same for TXT and ABS. The results were ranked, and a list of 30 keywords from the analysed articles related to the smart city was built.

\begin{tabular}{|c|c|c|c|}
\hline No. & Word & TXT & ABS \\
\hline 1 & smart & 1 & 1 \\
\hline 2 & data & 1 & 1 \\
\hline 3 & city & 1 & 1 \\
\hline 4 & system & 1 & 1 \\
\hline 5 & network & 1 & 1 \\
\hline 6 & base & 1 & 1 \\
\hline 7 & energy & 1 & 1 \\
\hline 8 & propose & 1 & 1 \\
\hline 9 & service & 1 & 1 \\
\hline 10 & time & 1 & 1 \\
\hline 11 & application & 1 & 1 \\
\hline 12 & information & 1 & 1 \\
\hline 13 & provide & 1 & 1 \\
\hline 14 & sensor & 1 & 1 \\
\hline 15 & device & 1 & 1 \\
\hline
\end{tabular}

\begin{tabular}{|c|c|c|c|}
\hline No. & Word & TXT & ABS \\
\hline 16 & technology & 1 & 1 \\
\hline 17 & node & 1 & 0 \\
\hline 18 & model & 1 & 0 \\
\hline 19 & communication & 1 & 1 \\
\hline 20 & resource & 1 & 1 \\
\hline 21 & result & 1 & 1 \\
\hline 22 & algorithm & 1 & 1 \\
\hline 23 & performance & 1 & 1 \\
\hline 24 & process & 1 & 0 \\
\hline 25 & iot & 0 & 1 \\
\hline 26 & monitor & 0 & 1 \\
\hline 27 & urban & 0 & 1 \\
\hline 28 & analysis & 0 & 0 \\
\hline 29 & method & 0 & 0 \\
\hline 30 & framework & 0 & 1 \\
\hline \multicolumn{4}{|c|}{} \\
\hline
\end{tabular}

Figure 5. Ranking of single words. Source: own work using R, Rstudio and MS Excel.

The same method was applied for 2-grams (bigrams). As the number of bigrams was large, only the 200 most common ones (in TXT and ABS) were considered. The grams were listed and ranked, and the most common phrases can be seen (Fig. 6, Fig. 7, Fig. 8). 


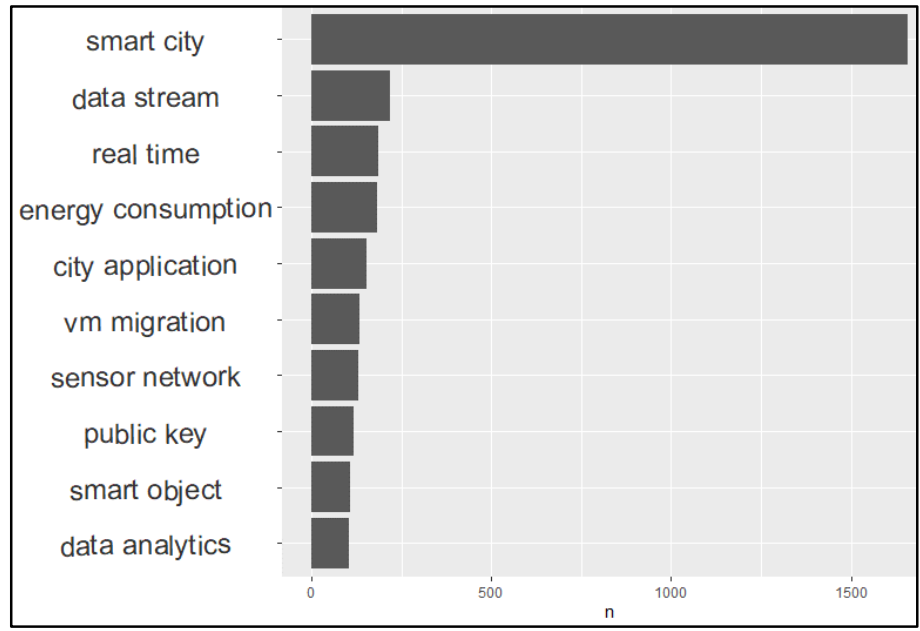

Figure 6. Bigrams (2-grams), whole articles without references (TXT). Source: own work.

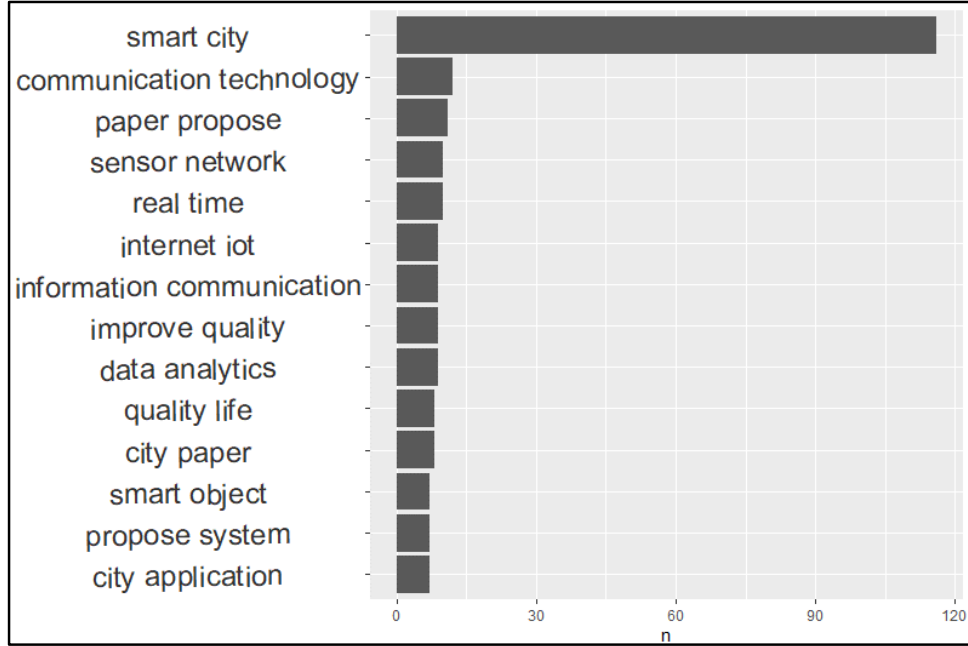

Figure 7. Bigrams (2-grams), abstracts (ABS). Source: own work. 


\begin{tabular}{|c|c|c|c|}
\hline No. & Word & TXT & ABS \\
\hline 1 & smart city & 1 & 1 \\
\hline 2 & real time & 1 & 1 \\
\hline 3 & sensor network & 1 & 1 \\
\hline 4 & data analytics & 1 & 1 \\
\hline 5 & city application & 1 & 1 \\
\hline 6 & energy consumption & 1 & 1 \\
\hline 7 & smart object & 1 & 1 \\
\hline 21 & admm algorithm & 1 & 0 \\
\hline 22 & urban fabric & 1 & 0 \\
\hline 2 & cloud compute & 1 & 1 \\
\hline 9 & propose system & 1 & 1 \\
\hline 24 & collect data & 1 & 0 \\
\hline 10 & communication technology & 0 & 1 \\
\hline 11 & data stream & 1 & 0 \\
\hline 12 & decision support & 1 & 1 \\
\hline 13 & sink node & 1 & 1 \\
\hline 14 & step size & 1 & 1 \\
\hline 15 & data process & 1 & 0 \\
\hline 16 & base station & 1 & 1 \\
\hline 17 & direction estimation & 1 & 1 \\
\hline 18 & system smart & 0 & 1 \\
\hline 19 & wireless sensor & 0 & 0 \\
\hline 28 & fog compute & 0 & 1 \\
\hline 29 & city smart & 0 & 1 \\
\hline & & 16 & 17 \\
\hline 30 & propose framework & 0 & 0 \\
\hline 31 & healthcare system & 1 & 0 \\
\hline 32 & mobile cloud & 1 & 0 \\
\hline 33 & data set & 0 & 0 \\
\hline 34 & propose method & 1 & 0 \\
\hline 35 & completion time & 0 & 0 \\
\hline 36 & machine learn & 0 & 0 \\
\hline 37 & development smart & 0 & 1 \\
\hline 38 & energy requirement & 0 & 0 \\
\hline 39 & smart healthcare & 0 & 1 \\
\hline 40 & internet iot & 0 & 1 \\
\hline
\end{tabular}

Figure 8. Ranking of bigrams (2-grams). Source: own work using R, Rstudio and MS Excel.

Approx. 171,000 trigrams were identified in the TXT set, about 93\% of which occurred only once. Approx. 5,614 trigrams were identified in the ABS set, about $98 \%$ of which occurred only once. The ranking includes only those phrases that occur more than once in the ABS and TXT sets. The trigrams were ranked by frequency. The author removed very common phrases found only in single articles, which resulted in an interesting list of phrases related to the smart city.

Table 2.

Phrases (3-grams)

\begin{tabular}{|c|c|}
\hline No. & Words \\
\hline 1 & smart city application \\
\hline 2 & wireless sensor network \\
\hline 3 & smart city service \\
\hline 4 & information communication technology \\
\hline 5 & base smart city \\
\hline 6 & system smart city \\
\hline 7 & energy requirement sink \\
\hline 8 & development smart city \\
\hline 9 & support vector machine \\
\hline 10 & decision support system \\
\hline
\end{tabular}

\begin{tabular}{|c|c|}
\hline No. & Words \\
\hline 11 & system delivery capacity \\
\hline 12 & smart city provide \\
\hline 13 & deploy smart city \\
\hline 14 & improve quality life \\
\hline 15 & smart city emerge \\
\hline 16 & smart healthcare system \\
\hline 17 & real time data \\
\hline 18 & automatic voice disorder \\
\hline 19 & mobile cloud compute \\
\hline 20 & intelligent transportation system \\
\hline
\end{tabular}

Source: own work. 
The last analytical stage of the proposed method was to apply word statistics and analysis of correspondence to group documents and relevant technologies. It was a challenge to select keywords for correspondence tables. Different words (variables) yielded different plots. Moreover, the large number of documents and keywords hindered clarity and conclusions. After several dozen trials, the author selected seven keywords related to technology that were the most common in the articles for abstracts and full texts, singular words (Fig. 5) and trigrams (Table 2). The selected words were application, network, service, information, base, system and energy.

Table 3.

Correspondence table for whole articles, TXT from 1 to 20

\begin{tabular}{|c|c|c|c|c|c|c|c|c|c|c|c|c|c|c|c|c|c|c|c|c|}
\hline & \multicolumn{10}{|c|}{ Article } \\
\hline & $\mathbf{1}$ & $\mathbf{2}$ & $\mathbf{3}$ & $\mathbf{4}$ & $\mathbf{5}$ & $\mathbf{6}$ & $\mathbf{7}$ & $\mathbf{8}$ & $\mathbf{9}$ & $\mathbf{1 0}$ & $\mathbf{1 1}$ & $\mathbf{1 2}$ & $\mathbf{1 3}$ & $\mathbf{1 4}$ & $\mathbf{1 5}$ & $\mathbf{1 6}$ & $\mathbf{1 7}$ & $\mathbf{1 8}$ & $\mathbf{1 9}$ & $\mathbf{2 0}$ \\
\hline system & 37 & 56 & 21 & 13 & 34 & 18 & 47 & 40 & 1 & 44 & 9 & 13 & 11 & 93 & 18 & 33 & 78 & 46 & 61 & 30 \\
\hline network & 8 & 64 & 7 & 32 & 67 & 10 & 20 & 25 & 28 & 3 & 77 & 26 & 23 & 8 & 8 & 44 & 283 & 9 & 7 & 3 \\
\hline energy & 231 & 101 & 5 & 0 & 78 & 3 & 11 & 147 & 57 & 1 & 64 & 0 & 24 & 8 & 30 & 3 & 18 & 4 & 0 & 3 \\
\hline application & 4 & 44 & 136 & 1 & 7 & 18 & 127 & 0 & 9 & 15 & 11 & 18 & 15 & 6 & 11 & 16 & 122 & 12 & 32 & 10 \\
\hline service & 3 & 55 & 37 & 4 & 6 & 13 & 338 & 1 & 1 & 15 & 0 & 19 & 19 & 12 & 14 & 26 & 31 & 35 & 24 & 1 \\
\hline base & 9 & 23 & 52 & 41 & 23 & 74 & 14 & 2 & 40 & 36 & 7 & 23 & 19 & 26 & 48 & 37 & 59 & 9 & 34 & 25 \\
\hline information & 10 & 26 & 42 & 4 & 39 & 5 & 26 & 37 & 9 & 9 & 17 & 4 & 47 & 15 & 7 & 6 & 9 & 38 & 10 & 19 \\
\hline
\end{tabular}

Source: own work.

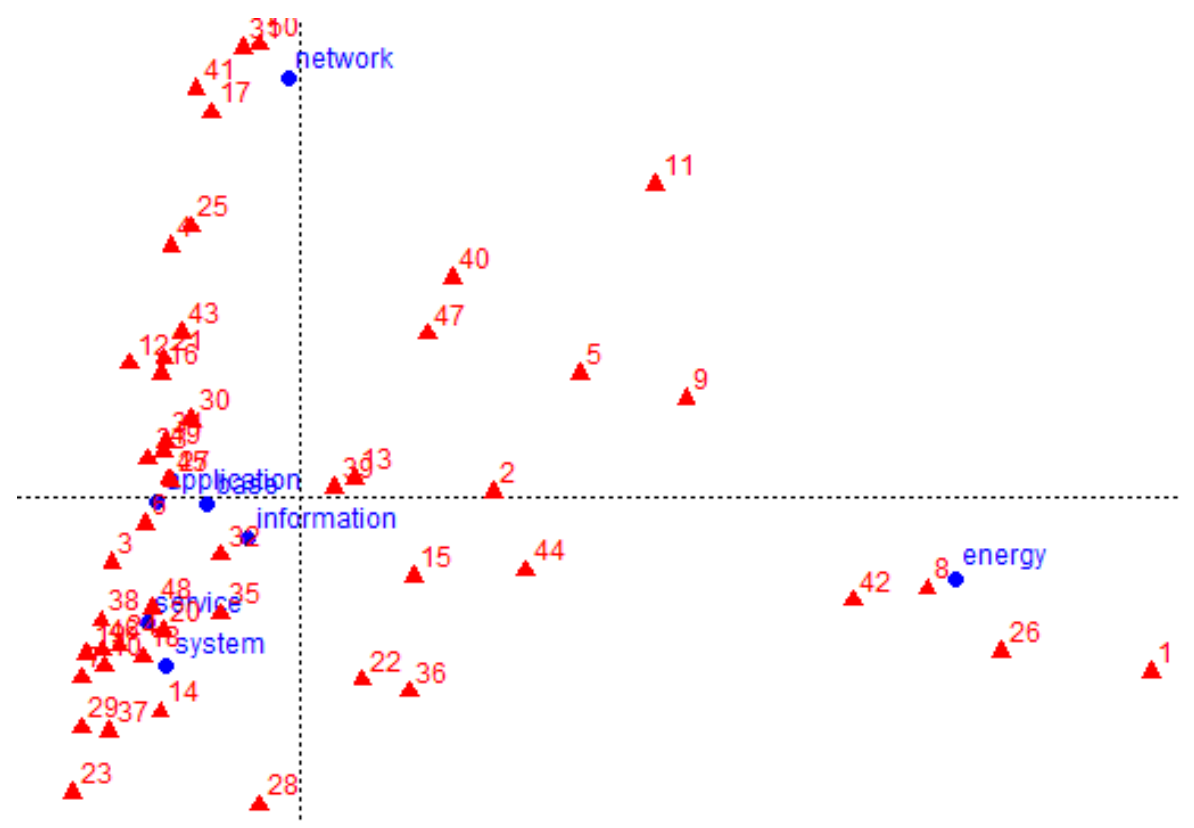

Figure 9. A correspondence analysis, complete texts (TXT). Source: own work. 


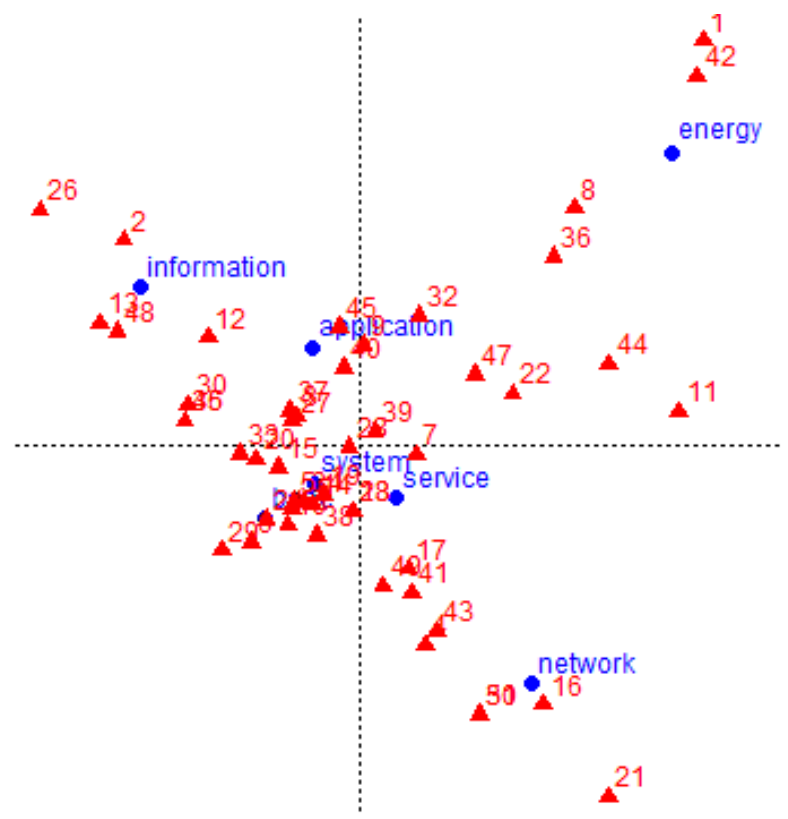

Figure 10. A correspondence analysis, abstracts (ABS). Source: own work.

The graphs show that the analysis of abstracts only partially corresponds to the analysis of whole documents. Some specific articles, however, can be clustered around certain issues and areas. Articles 1, 8 and 42, for example, focus on energy. Analysis of complete texts (TXT) shows that article 26 can join this group as well. Graphs for abstracts (ABS) do not correspond fully to the analysis of whole documents (TXT). Hence, analysis of whole documents together with abstracts yields better and more precise results. An excessive number of words or word variables distorts plot analysis.

In the central part of the plot for abstracts (ABS), there is 'system'. For complete texts (TXT), these are 'application', 'system', 'base', 'service' and 'information'. These notions can be associated with technology.

Articles can be grouped by areas of application of systems and technologies to improve the functioning of the city. Four examples of areas were identified: security, environment, energy and healthcare (Fig. 11). 


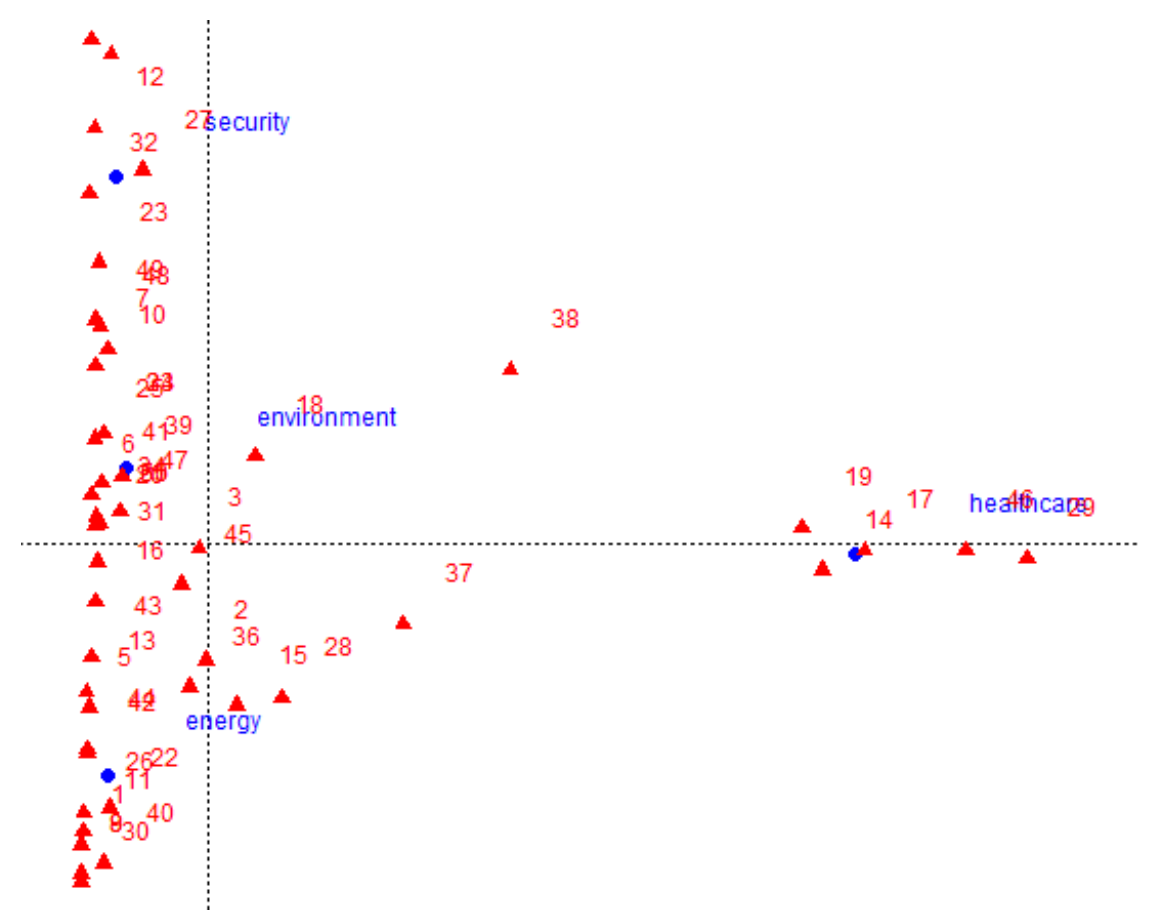

Figure 11. A correspondence analysis, complete texts (TXT) 2. Source: own work.

Further analyses of correspondence involved various combinations of keywords related to technologies or their respective areas of application. Preliminary results confirmed that it was reasonable to conduct correspondence analyses of abstracts and complete texts simultaneously. In this way, similar articles related to the smart city could be preliminarily grouped.

\section{Discussion and conclusion}

In the current era of global digitalisation and Internet prevalence, the amount of textual data is prolific. IDC predicts that the collective sum of the world's data will grow from 33 zettabytes in 2018 to 175 zettabytes by 2025, for a compound annual growth rate of 61 per cent. The 175 zettabytes figure represents a 9 per cent increase over last year's prediction of data growth by 2025 (Networkworld 2019, Reinsel et al. 2018). Domo's reports Data Never Sleeps 5.0 (2017) and Data Never Sleeps 6.0 (2018) demonstrate the colossal amount of data created in one minute of a year. According to the reports, users published on average 49 thousand photographs on Instagram and performed 3.8 million Google searches in a minute at the end of 2018. The same applies to the continually growing number of research publications.

There is, therefore, a reason to create and use simple methods of data exploration that can be used by managers and researchers in various fields to aid their decision-making. Among them are combinations of text mining and correspondence analysis. 
When used for the first time, analysis of research articles on the smart city using text mining is very time-consuming. The primary reason is that scripts need to be written and then adjusted when analysing unstructured texts. Additionally, excessive variability of templates used in PDF research articles hinders analysis and significantly increases the time needed for data clean-up. A mere fifty articles from just two sources were enough to support conclusions regarding research domains appearing in the context of the smart city. They are primarily domains related to technologies and systems employed to improve the functioning of the city. The articles can be grouped by application areas for the systems and technologies. It is especially useful when searching for articles on a specific aspect of the smart city (such as energy). This is not an easy challenge, however. Articles have to be properly selected and thoroughly cleaned. Single-word analysis is not enough as well; two-word and three-word phrases should be considered for whole articles and abstracts. The selection of the right number of articles and words for correspondence analysis is just as important.

Text mining offers ample analytical possibilities, and it all depends on the needs and skills of the user. When applied to research texts, it can be used to pose new research questions as needed based on previous results. This is why it is so important to create simple, useful tools and methods for analysing unstructured text documents, which can be used not only by data science researchers, but also managers or other researchers to make decisions based on reliable, unstructured textual data.

The present paper proposes the foundations of a text mining method for analysing documents concerning the smart city. Anyone attempting to analyse research articles with the proposed method of text mining and procedural steps should account for its limitations. These are related mostly to diagrams, tables and figures in PDF files, which are omitted although they might contain valuable information. Text mining can be employed by various experts focusing on the smart city and constitute an interesting complement for other research methods, such as questionnaire surveys, interviews or observations.

Future work should include further refinement of the assumptions for the method, analyses of a more significant number of research texts and a narrowing down of the domain of the smart city. The method can also be used to monitor the dynamics of changes in the popularity of various new technologies and systems in different functional areas of the smart city over time.

\section{References}

1. Albino, V., Berardi, U., \& Dangelico, R.M. (2015). Smart cities: Definitions, dimensions, performance, and initiatives. Journal of urban technology, 22(1), 3-21.

2. Internet source: Wikipedia - Smart city, Available online https://en.wikipedia.org/wiki/ Smart_city, 29.10.2019. 
3. Deakin, M. (Ed.) (2013). Smart cities: governing, modelling and analysing the transition. Routledge.

4. Deakin, M., \& Al Waer, H. (2011). From intelligent to smart cities. Intelligent Buildings International, 3(3), 140-152.

5. Internet source: Web of Science, Available online https://apps.webofknowledge.com, 28.11.2019.

6. Internet source: Google Trends, Available online https://trends.google.com/trends/ explore?date $=2008-01-01 \% 202020-01-02 \& q=\% 22$ smart $\% 20$ city $\% 22,28.11 .2019$.

7. Internet source: Networkworld article, Available online https://www.networkworld.com/ article/3325397/idc-expect-175-zettabytes-of-data-worldwide-by-2025.html, 28.11.2019.

8. Reinsel, D., Gantz, J., \& Rydning, J. (2018). The digitisation of the world: from edge to core. Framingham: International Data Corporation. Available online: https://www.seagate.com/files/www-content/our-story/trends/files/idc-seagate-dataagewhitepaper.pdf, 11.12.2019.

9. Internet source: Report: Data Never Sleeps, Available online https://www.domo.com/ learn/data-never-sleeps-5, https://www.domo.com/learn/data-never-sleeps-6, 28.11.2019.

10. Suhaib Peerzada. What is Text Mining? - The Complete Beginner's Guide (5.07.2018). Available online https://www.digitalvidya.com/blog/what-is-text-mining-guide, 14.11.2019.

11. Fan, W., Wallace, L., Rich, S., \& Zhang, Z. (2006). Tapping the power of text mining. Communications of the ACM, 49(9), 76-82.

12. Vijayarani S., Ilamathi J., Nithya, Phil M., (2015), Preprocessing Techniques for Text Mining - An Overview. International Journal of Computer Science \& Communication Networks, Vol 5(1), 7-16.

13. Silge, J., Robinson, D. (2017). Text mining with R: A tidy approach. O'Reilly Media, Inc. Available online https://www.tidytextmining.com/index.html, 10.11.2019.

14. Internet source: EASE Guidelines for Authors and Translators of Scientific Articles to be Published in English. Available online https://ease.org.uk/publications/author-guidelinesauthors-and-translators, 11.12.2019.

15. Mogull, S.A. (2017). Scientific and medical communication: a guide for effective practice. Routledge.

16. Sollaci, L.B., \& Pereira, M.G. (2004). The introduction, methods, results, and discussion (IMRAD) structure: a fifty-year survey. Journal of the medical library association, 92(3), 364.

17. Nakagawa, T., \& Uchimoto, K. (2007, June). A hybrid approach to word segmentation and pos tagging. Proceedings of the 45th Annual Meeting of the Association for Computational Linguistics Companion Volume Proceedings of the Demo and Poster Sessions, pp. 217220. 